\title{
A Letter in Response to "Diagnosing Catheter-Associated Urinary Tract Infection in Critically ill Patients: Do the Guidelines Help?"
}

Sir,

I read with interest the review article by Saran et al. ${ }^{[1]}$ where the authors have suggested an approach to catheter-associated urinary tract infection (CAUTI) in catheterized patients with fever in Intensive Care Units (ICUs). The Centers for Disease Control and Prevention-National Health Safety Network (CDC-NHSN) CAUTI definition excluded Candida as a valid causative organism based on several factors: "Candida is a rare cause of UTI but urinary catheter colonization is common in some patient populations; treatment of candiduria is not associated with clinical benefit; and the inclusion of Candida in the definition may encourage inappropriate antifungal prescribing." ${ }^{\text {[2] }}$ It is also to be emphasized that the CDC-NHSN CAUTI definitions are primarily for surveillance purposes only, whereas the definitions of Infectious Diseases Society of America (IDSA) are largely concerned with diagnosis as well as patient management. In this context, I would like to make the following modifications to the suggested managerial approach for CAUTI in ICU settings.

i. In Figure 2, under risk factors, total parenteral nutrition can be added for medical ICU and specific risk factors such as anastomic leakage, surgery of the large bowel, and necrotizing pancreatitis can be added for surgical ICU to the rsik factors already described in the risk factor in article by Saran et al. Similarly, for neonatal ICUs, the risk factors are different and may not be under the purview of the present review

ii. In Figure 2, under urine culture/sensitivity, it is recommended by the IDSA to remove the indwelling catheter and insert a new one (if still clinically indicated), with the urine specimen to be collected from the freshly placed catheter, before initiation of antibiotics/antifungal therapy for symptomatic infection. ${ }^{[3]}$ This measure mitigates the effect of biofilms formed on the lumen of the catheter and hitherto contamination of urine specimen with microorganisms of the biofilm

iii. Candida score and/or Candida Colonization Index is not practiced in many ICUs. Furthermore, the predictive values of these scores are not validated for every ICU setting. ${ }^{[4]}$ Putting these into algorithm will put extra burden on laboratories as well as patients.

And finally, disregarding Candida as a causative agent of 
CAUTI in hospitals/centers who follow CDC-NHSN CAUTI definitions will not only have its implications on CLABSI rates, but also put the onus on Candida auris surveillance in India. ${ }^{[5,6]}$

\section{Financial support and sponsorship \\ Nil.}

\section{Conflicts of interest}

There are no conflicts of interest.

Bijayini Behera

Department of Microbiology, All India Institute of Medical Sciences, Bhubaneswar, Odisha, India

Address for correspondence: Dr. Bijayini Behera, Associate Professor, Department of Microbiology, All India Institute of Medical Sciences, Bhubaneswar - 751 019, Odisha, India. E-mail: drbinny2004@gmail.com

\section{RefEREnCES}

1. Saran S, Rao NS, Azim A. Diagnosing catheter-associated urinary tract infection in critically Ill patients: Do the guidelines help? Indian J Crit Care Med 2018;22:357-60.

2. Kieffer P, Gase KA, Babcock HM, Leone C, Snyders R, Hoehner C, et al. Removing yeast from the catheter-associated urinary tract infection definition: The impact on rates for a large healthcare system. Am J Infect Control 2015;43:S6.

3. Hooton TM, Bradley SF, Cardenas DD, Colgan R, Geerlings SE, Rice JC, et al. Diagnosis, prevention, and treatment of catheter-associated urinary tract infection in adults: 2009 International Clinical Practice Guidelines from the Infectious Diseases Society of America. Clin Infect Dis 2010;50:625-63.
4. De Rosa FG, Corcione S, Montrucchio G, Brazzi L, Di Perri G Appropriate treatment of invasive candidiasis in ICU: Timing, colonization index, candida score \& biomarkers, towards de-escalation? Turk J Anaesthesiol Reanim 2016;44:279-82.

5. Fakih MG, Groves C, Bufalino A, Sturm LK, Hendrich AL. Definitional change in NHSN CAUTI was associated with an increase in CLABSI events: Evaluation of a large health system. Infect Control Hosp Epidemiol 2017;38:685-9.

6. Candida auris in Healthcare Settings India. Indian Council of Medical Research (ICMR). Available from: http://www.icmr.nic.in/icmrnews/ candida\%20auris.pdf. [Last accessed on 2018 May 23].

This is an open access journal, and articles are distributed under the terms of the Creative Commons Attribution-NonCommercial-ShareAlike 4.0 License, which allows others to remix, tweak, and build upon the work non-commercially, as long as appropriate credit is given and the new creations are licensed under the identical terms.

\begin{tabular}{|l|l|}
\hline \multicolumn{3}{|c|}{ Access this article online } \\
\hline Quick Response Code: & Website: \\
& www.ijccm.org \\
& \\
\hline
\end{tabular}

How to cite this article: Behera B. A letter in response to "Diagnosing catheter-associated urinary tract infection in critically ill patients: Do the guidelines help?". Indian J Crit Care Med 2018;22:467-8.

C 2018 Indian Journal of Critical Care Medicine | Published by Wolters Kluwer - Medknow 